\title{
On the Estimation of Permeabilities and Draw Resistances of Cigarette Components*
}

\author{
by \\ Bernhard Eitzinger \\ WFT Research, Fabrikstrasse 20, 4050 Traun, Austria
}

\section{SUMMARY}

The goal of this study is to investigate whether the permeability of the tipping/plugwrap system, the permeability of the cigarette paper and the draw resistances of the filter and tobacco rod can be calculated from measurements of the degree of filter ventilation and of the open and closed draw resistance. This issue is investigated for a linear and a nonlinear model of the flow in unlit cigarettes. At first it is proven that there exist experimental conditions to which the cigarette can be exposed such that the problem has at least a unique solution. The problem is then solved by least-squares optimisation for a linear and a non-linear model of the air flow in unlit cigarettes with various noise levels on the output quantities. The error sensitivity of the optimisation problem is estimated by calculation of the condition number.

From the simulation several facts can be concluded. Firstly, for the linear model varying the flow velocity at the mouth end of the cigarette does not provide enough information to uniquely determine the properties of the cigarette's components. Secondly, estimates of these properties from the linear model have low standard deviations but a high bias, which makes the linear model useless for the estimation task. Thirdly, estimates from the non-linear model are more reliable if the pressure at the cigarette tip is varied instead of the flow velocity at the mouth end. Fourthly, the measurements of the degree of filter ventilation and of the open and closed draw resistance need to be at least 10 to 20 times more accurate than the desired accuracy of the estimate. Several methods to improve this situation are proposed. [Beitr. Tabakforsch. Int. 21 (2004) 25-31]

\section{ZUSAMMENFASSUNG}

Das Ziel dieser Untersuchung ist festzustellen, ob durch Messung von Filterventilationsgrad sowie offenem und geschlossenem Zugwiderstand die Permeabilität des Mundstückbelag-/Filterhüllpapiers, die Permeabilität des Zigarettenpapiers und die Zugwiderstände von Filter und Tabak- strang bestimmt werden können. Die Untersuchungen werden anhand eines linearen und eines nichtlinearen Strömungsmodells einer Zigarette durchgeführt. Zunächst wird gezeigt, dass durch die Festlegung einer ausreichenden Zahl von Randbedingungen das Problem zumindest eine eindeutige Lösung besitzt. Die unbekannten Stömungsparameter des linearen und nichtlinearen Modells werden dann mit Hilfe des Least-Squares Verfahrens aus ,gemessenen” Werten für den Filterventilationsgrad und den offenen und geschlossenen Zugwiderstand bestimmt, wobei die ,gemessenen" Werte durch das nichtlineare Modell simuliert und mit zufälligem Rauschen versehen werden. Die Fehlerempfindlichkeit des Optimierungsproblems wird durch dessen Konditionszahl abgeschätzt.

Aus den Simulationen können mehrere Schlussfolgerungen gezogen werden. Zunächst genügt es nicht, die Strömungsgeschwindigkeit am Mundende der Zigarette zu variieren, wenn die Parameter mit Hilfe eines linearen Modells bestimmt werden sollen. Weiters zeigen Parameterschätzungen aus dem linearen Modell zwar geringe Standardabweichungen aber recht große Fehler im Mittelwert, wodurch das lineare Modell zur Parameterschätzung unbrauchbar wird. Parameterschätzungen mit Hilfe des nichtlinearen Modells erweisen sich als genauer, insbesondere dann, wenn statt der Strömungsgeschwindigkeit am Mundende der Luftdruck an der Zigarettenspitze variiert wird. Trotzdem müssen die Messwerte von Filterventilationsgrad sowie offenem und geschlossenem Zugwiderstand mindestens um einen Faktor 10 bis 20 genauer sein als die gewünschte Genauigkeit der zu schätzenden Parameter. Verschiedene Möglichkeiten werden angegeben, um diese Situation zu verbessern. [Beitr. Tabakforsch. Int. 21 (2004) 25-31]

\section{RESUME}

L'objectif de cette étude est de savoir s'il est possible de calculer la perméabilité du papier-manchette, du papier à cigarettes ainsi que les résistances au tirage du filtre et du boudin de tabac par la mesure du degré de ventilation du 
filtre et de la résistance au tirage ouverte et fermée. Cette question a été étudiée à l'aide d'un modèle d'écoulement linéaire et non-linéaire dans une cigarette non allumée. Plusieurs conditions expérimentales sont proposées prouvant qu'il y a une solution unique à ce problème. Ce problème d'optimisation est résolu, pour le modèle linéaire et nonlinéaire du flux dans des cigarettes non allumées, par différents niveaux de bruit s'intensifiant sur les valeurs de départ. Les erreurs surgissant dans la procédure d'optimisation ont été estimées par le calcul du nombre de conditions.

Les simulations permettent de tirer plusieurs conclusions. Premièrement, il ne suffit pas de faire varier la vitesse d'écoulement au niveau de la manchette de la cigarette pour déterminer les propriétés des composants de cigarettes à l'aide du modèle linéaire. Deuxièmement, les estimations à partir du modèle linéaire démontrent des déviationsstandard insignifiantes, mais des erreurs considérables dans la moyenne. Le modèle linéaire n'est donc pas approprié pour l'estimation des paramètres. Troisièmement, les estimations à partir du modèle non-linéaire sont plus fiables si la pression d'air au bout de la cigarette est variée, au lieu de la vitesse d'écoulement à la manchette. Quatrièmement, les résultats de la mesure du degré de ventilation du filtre et de la résistance au tirage ouverte et fermée doivent être 10 à 20 fois plus exacts que l'exactitude désirée des paramètres à estimer. Plusieurs méthodes pour améliorer cette situation sont proposées. [Beitr. Tabakforsch. Int. 21 (2004) 25-31]

\section{INTRODUCTION}

A mathematical model of an unlit cigarette can be used on the one hand to predict the degree of filter ventilation and the draw resistance of a cigarette if the properties of its components are known, and on the other hand it can be used to estimate the properties of its components if the degree of filter ventilation and the draw resistance have been measured. Most models have been derived and used for the former purpose, for example, in (1), (2), (3), but the latter problem, the so called inverse problem, is also of technical importance and is the topic of this study. A first attempt at solving the inverse problem was made in (4), but the method proposed therein requires that the cigarette is disassembled and some special measurements performed on the cigarette. It also deals only with the cigarette paper permeability. In contrast, it will be investigated here whether the inverse problem can be solved without disassembling the cigarette and by using only routine measurements, like the degree of filter ventilation and the open and closed draw resistance. Under "open draw resistance" we understand the pressure difference between both ends of the cigarette at an air flow of $17.5 \mathrm{~cm}^{3} / \mathrm{s}$, while under "closed draw resistance" we understand the pressure difference measured at the same air flow rate but with blocked ventilation holes.

Briefly, the following problem will be solved: Given the degree of filter ventilation and the open and closed draw resistance, determine the permeabilities of the tipping paper/plug wrap paper combination (TP/PW), the permeability of the cigarette paper and the draw resistances of filter and tobacco rod.
A solution of this problem may be useful, for example, in cigarette design, if the properties of cigarette components need to be calculated from the specifications of the cigarette. It may also be useful as a troubleshooting tool in quality assurance, if one wants to find out which component of the cigarette caused a deviation from the cigarette's specifications.

The main focus of this study will be on the second question, but with minor modifications the first one can be answered as well.

\section{GENERAL THEORY}

To state the problem from a mathematical point of view, some basic results from differential geometry, numerical linear algebra and optimisation theory will be introduced. The details can be found, for example, in (5), (6) and (7). We will consider a sufficiently often continuously differentiable function $f: X \times \Theta \rightarrow Y$ which maps experimental conditions $X$ and parameters $\Theta$ to some output quantities $Y$. The sets $X, \Theta$ and $Y$ are assumed to be open and simply connected subsets of some finite dimensional real space. The norm used throughout this study will be the 2-norm $\|\cdot\|_{2}$ for vectors and the spectral norm as the induced operator norm for matrices.

Later on $f$ will represent the cigarette model which maps the set of experimental conditions, that is, the flow velocity at the mouth end and the pressure at the cigarette tip to three output quantities. These output quantities are the degree of filter ventilation, the open draw resistance and the closed draw resistance. The cigarette model $f$ is parameterised by the permeability of the tipping/plug wrap system, the cigarette paper permeability and the draw resistances of the filter and tobacco rod.

We assume that a set of experimental conditions $\boldsymbol{x}_{i} \in X$ is known and the output quantities $\boldsymbol{y}_{i} \in Y, i=1,2, \ldots, N$, have been measured for the experimental conditions $\boldsymbol{x}_{i}$. The determination of the unknown parameters is then equivalent to finding a parameter vector $\theta$ which simultaneously satisfies $\boldsymbol{f}\left(\boldsymbol{x}_{i}, \boldsymbol{\theta}\right)=\boldsymbol{y}_{i}$ for $i=1,2, \ldots, N$. This can be written as a large system of equations

$$
\boldsymbol{g}(\theta)=\left[\begin{array}{c}
\boldsymbol{f}\left(\boldsymbol{x}_{1}, \theta\right) \\
\boldsymbol{f}\left(\boldsymbol{x}_{2}, \theta\right) \\
\vdots \\
\boldsymbol{f}\left(\boldsymbol{x}_{N}, \theta\right)
\end{array}\right]=\left[\begin{array}{c}
\boldsymbol{y}_{1} \\
\boldsymbol{y}_{2} \\
\vdots \\
y_{N}
\end{array}\right]=y_{0}
$$

\section{Uniqueness of the solution}

In the general case if $\operatorname{dim}(\Theta)>N \cdot \operatorname{dim}(Y)$ no unique solution can be found. Therefore we assume that at least as many measured outputs are available as there are parameters. Then the following theorem holds (5).

Let $g: \Theta \rightarrow Y^{N}$ be a function with $\operatorname{dim}(\Theta) \leq N \cdot \operatorname{dim}(Y)$. If the rank of the Jacobian matrix $\partial \mathbf{g} / \partial \boldsymbol{\theta}$ at $\theta_{0}$ equals $\operatorname{dim}(\Theta)$ then there exists an open neighbourhood of $\theta_{0}$ such that the inequality $\boldsymbol{g}\left(\theta_{1}\right) \neq \boldsymbol{g}\left(\theta_{2}\right)$ holds for all $\theta_{1}, \theta_{2}$ from this neighbourhood, with $\theta_{1} \neq \theta_{2}$. 


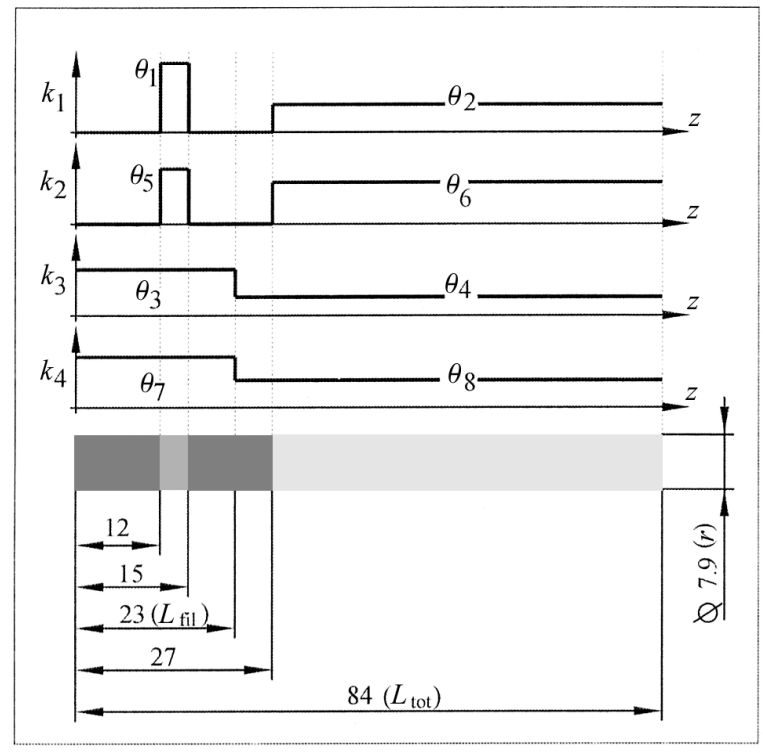

Figure 1. Geometry of the simulated cigarette and the permeability and draw resistance parameters along the cigarette

This theorem provides an easily applicable method to check whether a system of equations has a locally unique solution. It has to be noted, however, that the theorem works only locally and even if the Jacobian matrix is of full rank for all $\theta \in \Theta$ global uniqueness cannot be concluded.

In case $\operatorname{dim}(\Theta)<N \cdot \operatorname{dim}(Y)$ the system of equations $\boldsymbol{g}(\boldsymbol{\theta})$ $=\boldsymbol{y}_{0}$ is usually overdetermined and a solution can be found by converting the system of equations into an optimisation problem, for example, by

$$
\min _{\theta \in \Theta} \frac{1}{2}\left\|g(\theta)-y_{0}\right\|_{2}^{2}
$$

Apart from the uniqueness of the solution, which can be addressed by the above theorem, the question to what extent errors in $\boldsymbol{y}_{0}$ influence the solution of optimisation problem [2] will be crucial in the following analysis.

\section{Error bounds}

Let $\mathbf{A} \boldsymbol{\theta}=\boldsymbol{y}_{0}$ be an overdetermined linear system of equations with $\mathbf{A}$ of full rank and let $\theta_{0}$ be the solution of the optimisation problem

$$
\min _{\boldsymbol{\theta} \in \Theta} \frac{1}{2}\left\|\mathrm{~A} \theta-\boldsymbol{y}_{0}\right\|_{2}^{2}
$$

For the solution $\theta_{0}+\Delta \theta$ of the optimisation problem

$$
\min _{\boldsymbol{\theta} \in \Theta} \frac{1}{2}\left\|\mathrm{~A} \theta-y_{0}-\Delta y\right\|_{2}^{2}
$$

the following inequality holds in a first-order approximation

$$
\frac{\|\Delta \theta\|_{2}}{\left\|\theta_{0}\right\|_{2}} \leq \operatorname{cond}(\mathbf{R}) \frac{\left\|y_{0}\right\|_{2}}{\|\mathrm{~A}\|_{2}\left\|\theta_{0}\right\|_{2}} \frac{\|\Delta y\|_{2}}{\left\|y_{0}\right\|_{2}}
$$

where $\mathbf{A}=\mathbf{Q} \cdot[\mathbf{R ~ 0}]^{T}$ is the $\mathrm{QR}$-decomposition of $\mathbf{A}$. For regular matrices cond $(\mathbf{R})$ is the condition number defined by cond $(\mathbf{R})=\|\mathbf{R}\|_{2}\left\|\mathbf{R}^{-1}\right\|_{2}$. It is bounded from below by one and approaches infinity as $\mathbf{R}$ becomes singular. Large condition numbers are a sign that the solution is sensitive to errors. The condition number is a property of the matrix $\mathbf{A}$ itself and does not depend on the specific algorithm used to solve the linear system of equations.

For non-linear systems of equations $\boldsymbol{g}(\boldsymbol{\theta})=\boldsymbol{y}_{0}$ no equally simple bound can be given but if the errors $\Delta y$ are sufficiently small, it is reasonable to use inequality [3] as an estimate with $\mathbf{A}=\partial \boldsymbol{g}\left(\theta_{0}\right) / \partial \boldsymbol{\theta}$.

\section{THE CIGARETTE MODEL}

In order to determine the permeability of the tipping/plug wrap paper, the permeability of the cigarette paper and the draw resistances of the filter and tobacco rod, a mathematical model for the stationary flow in a cigarette is needed, whose predictions of the degree of filter ventilation and of the open and closed draw resistance can be compared with the measured values. Such models for the stationary flow in unlit cigarettes can be found in many publications, for example (1), (2), (3) and most of the models can be put into the form of a two-point boundary value problem as reproduced here.

$$
\begin{gathered}
\frac{d v}{d z}=\frac{2}{r}\left[k_{1}(z) p-k_{2}(z) \sqrt{|p|}\right] \\
\frac{d p}{d z}=k_{3}(z) v+k_{4}(z) v^{2} \\
v(0)=v_{0} \\
p\left(L_{\text {tot }}\right)=p_{0}
\end{gathered}
$$

where $v$ is the flow velocity in the negative $z$-direction and $p$ is the pressure difference with respect to environmental air pressure. Equations [4] are stated for the case $v \geq 0$ and $p \leq 0$, which agrees with the typical flow through cigarettes. The geometry of the cigarette and the functions $k_{i}(z), i=1,2,3,4$, are shown in Figure 1.

In the above notation we have $\boldsymbol{x}^{T}=\left[\begin{array}{ll}v_{0} & p_{0}\end{array}\right]$ for the experimental conditions and consequently $X=R^{2}$. The output quantities $\boldsymbol{y}^{T}=\left[\begin{array}{l}V \\ p_{\text {closed }} \\ p_{\text {open }}\end{array}\right]$ are the degree of filter ventilation, $V=1-v\left(L_{\mathrm{fil}}\right) / v_{0}$, the open draw resistance, $p_{\text {open }}$ $=p(0)$, and the closed draw resistance, $p_{\text {closed }}$ with tipping paper permeability set to zero.

The unknown parameters $\boldsymbol{\theta}^{T}=\left[\begin{array}{llll}\theta_{1} & \theta_{2} & \cdots & \theta_{8}\end{array}\right]$ are contained in the functions $k_{i}(z), i=1,2,3,4$, with $\theta_{1}$ and $\theta_{2}$ describing the permeability of the tipping/plug wrap system, $\theta_{2}$ and $\theta_{6}$ the cigarette paper permeability, $\theta_{3}$ and $\theta_{7}$ the draw resistance of the filter and $\theta_{4}$ and $\theta_{8}$ the draw resistance of the tobacco rod.

Therefore the cigarette model can be understood as a function $f: X \times \Theta \rightarrow Y$ which maps boundary values and parameters to the output quantities. In this study two models will be used, firstly, the full eight-parameter nonlinear model $f^{\text {nonlin }}: R^{2} \times R^{8} \rightarrow R^{3}$ and, secondly, a simplified 
Table 1. The nominal parameter values used in the linear and the non-linear model

\begin{tabular}{|c|c|c|c|c|}
\hline & $\begin{array}{l}\text { Non- } \\
\text { linear }\end{array}$ & Linear & Unit & Description \\
\hline$\theta_{1}$ & $4.20 e-5$ & $1.00 e-4$ & $\mathrm{~ms}^{-1} \mathrm{~Pa}^{-1}$ & $\begin{array}{l}\text { Tipping/plug wrap } \\
\text { permeability (linear) }\end{array}$ \\
\hline$\theta_{2}$ & $6.75 e-6$ & $8.33 e-6$ & $\mathrm{~ms}^{-1} \mathrm{~Pa}^{-1}$ & $\begin{array}{c}\text { Cigarette paper } \\
\text { permeability (linear) }\end{array}$ \\
\hline$\theta_{3}$ & $8.36 e+4$ & $8.36 e+4$ & $\mathrm{~m}^{-2} \mathrm{sPa}$ & $\begin{array}{l}\text { Draw resistance filter } \\
\text { (linear) }\end{array}$ \\
\hline$\theta_{4}$ & $2.24 e+4$ & $2.70 e+4$ & $\mathrm{~m}^{-2} \mathrm{sPa}$ & $\begin{array}{l}\text { Draw resistance tobacco } \\
\text { rod (linear) }\end{array}$ \\
\hline$\theta_{5}$ & $1.80 \mathrm{e}-3$ & & $\mathrm{~ms}^{-1} \mathrm{~Pa}^{-1 / 2}$ & $\begin{array}{l}\text { Tipping/plug wrap } \\
\text { permeability (non-linear) }\end{array}$ \\
\hline$\theta_{6}$ & $5.01 e-5$ & & $\mathrm{~ms}^{-1} \mathrm{~Pa}^{-1 / 2}$ & $\begin{array}{c}\text { Cigarette paper } \\
\text { permeability (non-linear) }\end{array}$ \\
\hline$\theta_{7}$ & 0.00 & & $\mathrm{~m}^{3} \mathrm{~s}^{2} \mathrm{~Pa}$ & $\begin{array}{l}\text { Draw resistance filter } \\
\text { (non-linear) }\end{array}$ \\
\hline$\theta_{8}$ & $1.29 \mathrm{e}+4$ & & $\mathrm{~m}^{3} \mathrm{~s}^{2} \mathrm{~Pa}$ & $\begin{array}{l}\text { Draw resistance tobacco } \\
\text { rod (non-linear) }\end{array}$ \\
\hline
\end{tabular}

Table 2. The output quantities of the model: degree of filter ventilation $V$, open draw resistance $p_{\text {open }}$ and closed draw resistance $p_{\text {closed }}$ calculated for various flow velocities at the mouth end $v_{0}$ and pressure differences at the cigarette tip $p_{0}$.

\begin{tabular}{l|r|r|r|r}
\hline & & \multicolumn{3}{|c}{ Non-linear model } \\
\cline { 3 - 5 } $\begin{array}{c}v_{0} \\
{\left[\mathrm{~ms}^{-1}\right]}\end{array}$ & $\begin{array}{c}p_{0} \\
{[\mathrm{~Pa}]}\end{array}$ & $V[\%]$ & $\begin{array}{c}p_{\text {open }} \\
{\left[\mathrm{mm} \mathrm{H}_{2} \mathrm{O}\right]}\end{array}$ & $\begin{array}{c}p_{\text {closed }} \\
{\left[\mathrm{mm} \mathrm{H}_{2} \mathrm{O}\right]}\end{array}$ \\
\hline 0.357 & 0 & 28.41 & 97.56 & 122.40 \\
0.179 & 0 & 33.45 & 45.58 & 59.02 \\
0.714 & 0 & 25.11 & 209.88 & 260.44 \\
0.357 & -500 & 39.29 & 131.57 & 164.96 \\
0.357 & -1000 & 49.78 & 167.24 & 208.24 \\
\hline
\end{tabular}

four-parameter linear model $f^{\text {in }}: R^{2} \times R^{4} \rightarrow R^{3}$ with $k_{2}(z)=$ $k_{4}(z)=0$ and hence $\theta_{5}=\theta_{6}=\theta_{7}=\theta_{8}=0$. Thus we have $\operatorname{dim}(\Theta)=8$ for the non-linear model and $\operatorname{dim}(\Theta)=4$ for the linear model.

It is clear that in order to determine a total of four or eight parameters the measurement of only three quantities is insufficient. Therefore an appropriate set of experimental conditions needs to be chosen. Firstly, a variation of the flow velocity $v_{0}$ at the mouth end will be considered by doubling and halving the standard volumetric flow of 17.5 $\mathrm{cm}^{3} / \mathrm{s}$. This yields the following set of boundary values,

$$
\begin{aligned}
& \boldsymbol{x}_{v, 1}^{T}=\left[\begin{array}{ll}
0.179 & 0
\end{array}\right] \\
& \boldsymbol{x}_{v, 2}^{T}=\left[\begin{array}{ll}
0.357 & 0
\end{array}\right] \\
& \boldsymbol{x}_{v, 3}^{T}=\left[\begin{array}{ll}
0.714 & 0
\end{array}\right]
\end{aligned}
$$

where the flow velocity is in $\left[\mathrm{ms}^{-1}\right]$ and the pressure in $[\mathrm{Pa}]$. Secondly, a variation of the pressure $p_{0}$ at the cigarette tip will be considered by introducing an additional pressure drop of $500 \mathrm{~Pa}$ and $1000 \mathrm{~Pa}$ at the cigarette tip. This yields the set

$$
\begin{aligned}
& \boldsymbol{x}_{p, 1}^{T}=\left[\begin{array}{ll}
0.357 & 0
\end{array}\right] \\
& \boldsymbol{x}_{p, 2}^{T}=\left[\begin{array}{ll}
0.357 & -500
\end{array}\right] \\
& \boldsymbol{x}_{p, 3}^{T}=\left[\begin{array}{ll}
0.357 & -1000
\end{array}\right]
\end{aligned}
$$

The two sets of boundary values [5] and [6] together with the linear and the non-linear model give a total of four combinations for the function $g: \Theta \rightarrow R^{9}$ as used in expression [1].

$$
\begin{gathered}
g_{v}^{\operatorname{lin}}(\theta)=\left[\begin{array}{l}
f^{\text {lin }}\left(x_{v, 1}, \theta\right) \\
f^{\operatorname{lin}}\left(x_{v, 2}, \theta\right) \\
f^{\operatorname{lin}}\left(x_{v, 3}, \theta\right)
\end{array}\right] \quad g_{p}^{\operatorname{lin}(\theta)}=\left[\begin{array}{l}
f^{\text {lin }}\left(x_{p, 1}, \theta\right) \\
f^{\operatorname{lin}}\left(x_{p, 2}, \theta\right) \\
f^{\text {lin }}\left(x_{p, 3}, \theta\right)
\end{array}\right] \\
g_{v}^{\text {nonlin }}(\theta)=\left[\begin{array}{l}
f^{\text {nonlin }}\left(x_{v, 1}, \theta\right) \\
f^{\text {nonlin }}\left(x_{v, 2}, \theta\right) \\
f^{\text {nonlin }}\left(x_{v, 3}, \theta\right)
\end{array}\right] g_{p}^{\text {nonlin }}(\theta)=\left[\begin{array}{l}
f^{\text {nonlin }}\left(x_{p, 1}, \theta\right) \\
f^{\text {nonlin }}\left(x_{p, 2}, \theta\right)
\end{array}\right]
\end{gathered}
$$

These four functions will be used for the simulations.

\section{NUMERICAL DETAILS}

The specifications for the cigarette used in the simulation are as follows, see also Figure 1.

$\begin{array}{lll}\text { TP/PW paper: } & \theta_{1}, \theta_{5} & 180 \mathrm{CU} \text { (CORESTA Unit) } \\ \text { Cigarette paper: } & \theta_{2}, \theta_{6} & 50 \mathrm{CU} \\ \text { Filter: } & \theta_{3}, \theta_{7} & 70 \mathrm{~mm} \mathrm{H}_{2} \mathrm{O} \\ \text { Tobacco rod: } & \theta_{4}, \theta_{8} & 60 \mathrm{~mm} \mathrm{H}_{2} \mathrm{O}\end{array}$

The pressure drops of the filter and tobacco rod are given for an air flow of $17.5 \mathrm{~cm}^{3} / \mathrm{s}$, the permeability is given in CORESTA units (CU) which is equal to $\mathrm{cm} \mathrm{min}^{-1} \mathrm{kPa}^{-1}$. The nominal values for the parameters were determined according to the known air flow/pressure drop relationships of electro-perforated tipping paper (3), porous plug wrap paper (8), porous cigarette paper (8) and typical filters and tobacco rods (9). The values are shown in Table 1 . With these parameter values the nominal degree of filter ventilation and the open and closed draw resistance were calculated for the non-linear model [4] with boundary values [5] and [6]. The results are shown in Table 2. To generate a "measured" output, normally distributed zero-mean random noise was added to the nominal output values from Table 2 . The parameters $\theta$ were then calculated by solving the optimisation problem [2] with the noisy output substituted for $\boldsymbol{y}_{0}$, and $g$ replaced by one of the functions in expression [7]. The parameter values as well as the output values vary by several orders of magnitude therefore all values were scaled to 1 to improve the accuracy of the numerical algorithm. As the specific algorithm used for the optimisation does not matter a trust-region Newton method was used as implemented in the function fminunc ( . . . ) in MATLAB's optimisation toolbox. The nominal parameter values were chosen as starting values for the optimisation algorithm. 


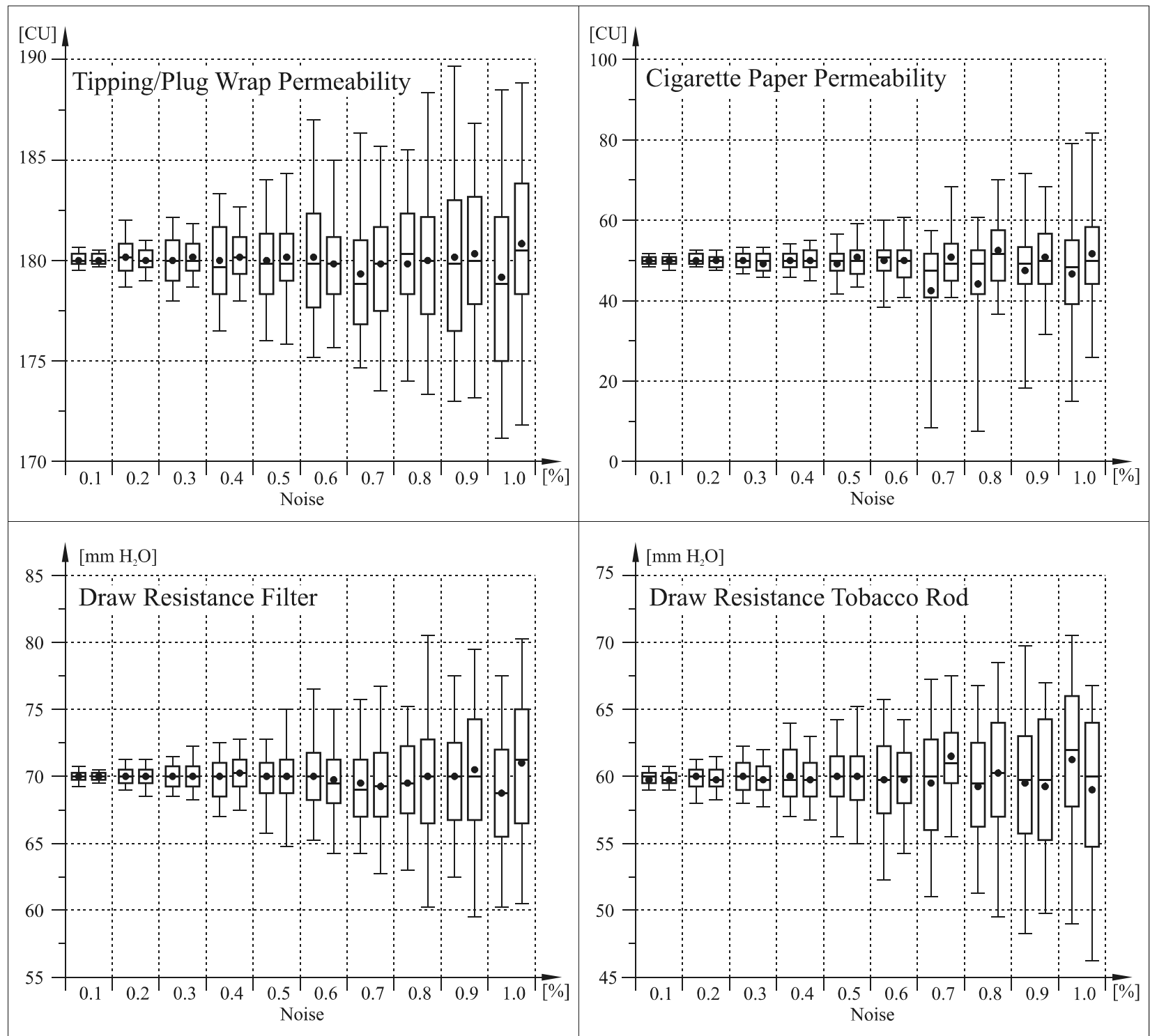

Figure 2. Mean and deviations of the estimated parameters with various noise levels on the output. The meaning of the boxes is explained in Figure 3.

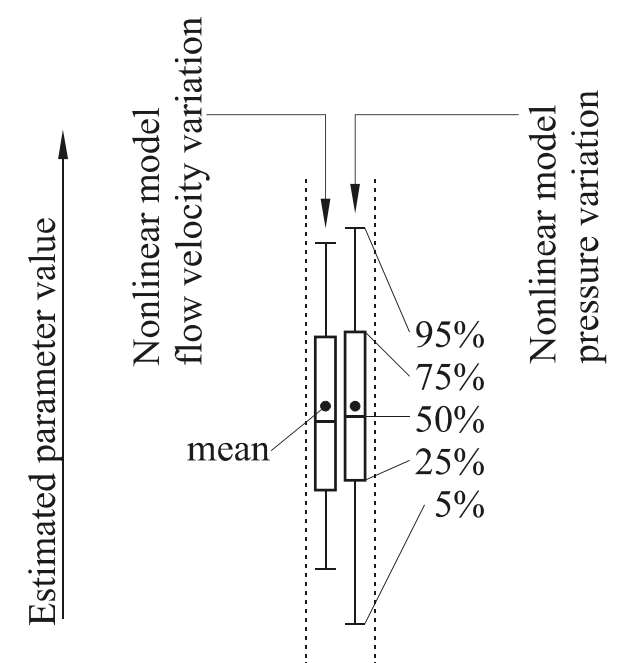

Noise level

Figure 3. Explanation of the boxes in Figure 2

\section{RESULTS}

In a first step the condition numbers were calculated for all four optimisation problems as shown in Table 3. These values provide an estimate of the worst-case error sensitivity of the optimisation problem.

While a worst-case estimate has the advantage of providing a hard upper bound it may be rather conservative. Therefore the statistical properties of the parameters were also calculated by simulation. The zero-mean normally distributed output noise was increased from a standard deviation of $0.1 \%$ up to $1 \%$ of the nominal value in 10 equidistant steps with 100 simulations per step. From the estimated parameters the paper permeabilities and the draw resistances were calculated. The results for the non-linear eight-parameter model are shown in Figures 2 and 3 for both flow velocity variation $\left(\boldsymbol{g}_{v}^{\text {nonlin }}\right)$ and pressure variation $\left(\boldsymbol{g}_{p}^{\text {nonlin }}\right)$. For reasons which will be explained below no meaningful results could be obtained for the linear model with flow velocity variation $\left(\boldsymbol{g}_{v}^{\operatorname{lin}}\right)$, therefore only the results for the linear model with pressure variation $\left(\boldsymbol{g}_{p}^{\operatorname{lin}}\right)$ are given in Table 4 . 
Table 3. The condition numbers of the four optimisation problems

\begin{tabular}{lc}
\hline & Condition number \\
\hline $\boldsymbol{g}_{v}^{\text {lin }}$ & $\infty$ \\
$\boldsymbol{g}_{p}^{\operatorname{lin}}$ & 24.503 \\
$\boldsymbol{g}_{v}^{\text {nonlin }}$ & 7251.463 \\
$\boldsymbol{g}_{p}^{\text {nonlin }}$ & 1096.021 \\
\hline
\end{tabular}

Table 4. The mean and standard deviation (StD) of the estimated permeabilities and draw resistances for various noise levels for the linear model. Errors are calculated for the $1 \%$ noise level. The CORESTA unit [CU] is equal to [cm min $\left.{ }^{-1} \mathrm{kPa}^{-1}\right]$.

\begin{tabular}{|c|c|c|c|c|c|}
\hline \multirow[b]{2}{*}{ Parameters } & & \multicolumn{3}{|c|}{ Noise } & \multirow{2}{*}{$\begin{array}{c}\text { Error } \\
{[\%]}\end{array}$} \\
\hline & & $0.1 \%$ & $0.5 \%$ & $1.0 \%$ & \\
\hline $\begin{array}{l}\text { TP/PW Paper } \\
\text { [CU] }\end{array}$ & $\begin{array}{l}\text { Mean } \\
\text { StD }\end{array}$ & $\begin{array}{r}162.77 \\
0.19\end{array}$ & $\begin{array}{r}162.62 \\
1.14\end{array}$ & $\begin{array}{r}162.31 \\
3.05\end{array}$ & -9.8 \\
\hline $\begin{array}{l}\text { Cigarette } \\
\text { paper [CU] }\end{array}$ & $\begin{array}{l}\text { Mean } \\
\text { StD }\end{array}$ & $\begin{array}{r}32.83 \\
0.23\end{array}$ & $\begin{array}{r}32.69 \\
1.69\end{array}$ & $\begin{array}{r}32.15 \\
3.94\end{array}$ & -35.7 \\
\hline $\begin{array}{l}\text { Filter } \\
\qquad\left[\mathrm{mm} \mathrm{H}_{2} \mathrm{O}\right]\end{array}$ & $\begin{array}{l}\text { Mean } \\
\text { StD }\end{array}$ & $\begin{array}{r}43.96 \\
0.15\end{array}$ & $\begin{array}{r}43.80 \\
1.15\end{array}$ & $\begin{array}{r}43.32 \\
3.38\end{array}$ & -38.1 \\
\hline $\begin{array}{l}\text { Tobacco rod } \\
{\left[\mathrm{mm} \mathrm{H}_{2} \mathrm{O}\right]}\end{array}$ & $\begin{array}{l}\text { Mean } \\
\text { StD }\end{array}$ & $\begin{array}{r}90.05 \\
0.20\end{array}$ & $\begin{array}{r}90.24 \\
1.17\end{array}$ & $\begin{array}{r}90.53 \\
3.50\end{array}$ & +50.9 \\
\hline
\end{tabular}

\section{DISCUSSION}

First of all one might be concerned how it is possible to draw general conclusions from calculations made for a single parameter vector $\theta_{0}$. As the function $\boldsymbol{g}$ is continuously differentiable with respect to the parameters, the Jacobian matrix $\partial g / \partial \theta$ will be of full rank on an open subset of $\Theta$ once this property has been established at a single point $\theta_{0}$. Furthermore, for all technically relevant boundary values, the non-linearity of the differential equation is only quantitative and not qualitative in nature and hence one may conjecture that the above mentioned open subset of $\Theta$ is rather large. For systems with real analytic $g$, of which the linear functions are a special case, even stronger conclusions can be made (10). Additionally it is easily possible to check the rank of the Jacobian matrix and to calculate its condition number for a very large set of parameters.

Therefore the conclusions can be formulated in a more general way than needs to be directly verified by numerical calculations.

\section{Worst-case properties}

The first point to be noted in Table 3 is that the condition number for the linear model used with flow velocity variation $\left(\boldsymbol{g}_{v}^{\operatorname{lin}}\right)$ is not finite. This means that the Jacobian matrix $\partial \boldsymbol{g}_{v} \operatorname{lin} / \partial \boldsymbol{\theta}$ is not of maximum rank and the parameters cannot be uniquely determined. Indeed as the model is linear and the boundary values are simply scalar multiples of each other $\left(4 \cdot \boldsymbol{x}_{v, 1}=2 \cdot \boldsymbol{x}_{v, 2}=\boldsymbol{x}_{v, 3}\right)$, the Jacobian matrix contains only three linearly independent rows. Therefore any one of the four parameters could be set to an arbitrary value and the remaining three are then uniquely determined. In contrast, the same model with variation of the pressure at the cigarette tip instead of the flow velocity at the mouth end gives a condition number of about 24.5. In view of its small size, the problem is reasonably but not well-conditioned. The condition numbers for the non-linear model are rather high, partially owing to the larger size of the problem. Although they are still orders of magnitude lower than $1.5 \cdot 10^{10}$ which is the condition number of the $8 \times 8$ Hilbert matrix, a matrix famous for being badly conditioned, they are 50 to 100 times higher than the average condition number of a $9 \times 8$ matrix with normally distributed elements. Table 3 also shows that from a worst-case point of view results obtained by varying the pressure at the cigarette tip instead of the flow velocity at the mouth end will be much more accurate. The condition numbers differ by a factor of approximately 6.6.

There are three main conclusions which can be drawn from the calculation of the condition numbers. Firstly, it is in principle possible to determine paper permeabilities and draw resistances of the components of a cigarette without disassembling the cigarette. Secondly, the predicted parameters will be more accurate if the pressure at the cigarette tip is varied instead of the flow velocity at the mouth end. Thirdly, if a linear model is used to estimate the parameters, a variation of the flow velocity alone does not provide enough information to determine the parameters.

\section{Statistical properties}

The statistical investigation for the linear model, Table 4, shows that although the standard deviations of the parameter estimates are quite low, there are large deviations from the correct parameter values. The reason for these deviations is that parameters of the linear model were fit to "measured" values calculated from the non-linear model. On the assumption that the non-linear model is fairly accurate, one has to conclude that in the present situation it does not make sense to use a linear model for the parameter estimation with real measured data.

For the non-linear model one observes that pressure variation gives slightly more accurate results than flow velocity variation, as has already been concluded from the condition numbers. Unfortunately, the standard deviations of the parameter estimates are rather high, especially for the cigarette paper permeability. In fact, devices used for measuring the degree of filter ventilation or draw resistances usually have coefficients of variation of about $1 \%$ which corresponds to the $1 \%$ noise level. At this noise level the cigarette paper permeability can only be predicted with a coefficient of variation of $30 \%$, which makes the estimate practically useless. Therefore it is worthwhile to take a closer look at the various sources of errors.

\section{Sources of errors}

The first and usually smallest source of errors is due to the finite precision of machine calculations. The machine precision of the floating-point numbers used in MATLAB is $2.2 \cdot 10^{-16}$, which, multiplied by the condition number, 
gives errors less than $10^{-11}$. Thus rounding errors are negligible. The second source of errors are convergence errors. The parameters are estimated in an iterative algorithm, which terminates after certain stopping criteria are satisfied. By estimating the parameters for an output without noise these errors could be verified to be smaller than $10^{-4}$. Thirdly, in practice even the non-linear model will not be a perfect description of the flow in an unlit cigarette. This introduces so called modelling errors which cannot be estimated by simulation.

There are several methods to further reduce the condition number. Appropriate scaling of parameters and output quantities has already been applied such that numerically not much more can be done. A regularization technique might also be of help, but it usually biases the parameter estimate. The condition number can also be reduced by using other boundary values, for example, combining the two sets of boundary values [5] and [6] will reduce the condition number by about $20 \%$ to 859.17 . This, however, is not a substantial gain.

Thus, looking at inequality [3] there remain two points of attack: the errors in the data $\Delta \boldsymbol{y}$ and the function $\boldsymbol{g}$ itself. The precision with which the output quantities are known can be improved by averaging the results of several measurements. Figure 2 shows that reasonable parameter estimates (below 3\% coefficient of variation) can be obtained if the noise level is below $0.2 \%$. This precision can be achieved, for example, by averaging at least 25 measurements performed on the same cigarette.

Perhaps a more significant improvement can be made by measuring different output quantities, that is, changing the function $\boldsymbol{g}$. If one is willing to disassemble the cigarette and measure the draw resistance of the encapsulated filter plug, two parameters can be eliminated. This reduces the condition number to 422.23 for the pressure variation and to 333.34 for a combination of both sets of boundary values [5] and [6].

The main conclusion from the statistical investigation is that in order to estimate the permeability of the tipping/plug wrap paper, the permeability of the cigarette paper and the draw resistances of the filter and tobacco rod from the degree of filter ventilation and the open and closed draw resistance the latter quantities need to be known at least 10 to 20 times more precisely than the desired accuracy of the parameter estimate. This fact is independent of the algorithm used to solve the inverse problem and therefore it has two major implications. Firstly, unless a high quality data set is available, destructive methods will usually deliver more exact and quicker results. Secondly, if the inverse problem appears as a sub-problem in cigarette design special care needs to be taken because its solution will be rather sensitive to changes in the cigarette's specifications.

\section{CONCLUSION}

It has been investigated whether and how the permeabilities of the tipping/plug wrap system and the cigarette paper as well as the draw resistances of the filter and tobacco rod can be estimated by measuring the degree of filter ventilation and the open and closed draw resistance. It was numerically verified for a linear and a non-linear model of the flow in unlit cigarettes that a unique set of parameters can be found. The inverse problem was transformed into a least-squares problem and numerically solved. The accuracy of the parameter estimate was evaluated by simulation with various levels of noise added to the output quantities. It was found that the degree of filter ventilation and the open and closed draw resistance need to be known at least an order of magnitude more precisely than the desired accuracy of the parameters. Various ways to improve this situation have been proposed.

\section{REFERENCES}

1. Dwyer R.W. and P. Chen: Prediction of pressure drop and ventilation in a lit cigarette; Beitr. Tabakforsch. Int. 18 (1999) 205-211.

2. Dwyer R.W., P. Chen, and R.D. Wasyk: A mathematical scheme for calculating flows and pressure drops in lit and unlit cigarettes; Beitr. Tabakforsch. Int. 19 (2001). 189-203

3. Eitzinger B. and G. Ederer: The use of nonlinear constitutive equations to evaluate draw resistance and filter ventilation; Beitr. Tabakforsch. Int. 19 (2001) 177-188.

4. Keith C.H.: The use of pressure drop measurements for estimating ventilation and paper porosity; Beitr. Tabakforsch. Int. 10 (1979) 7-16.

5. Lang S.: Fundamentals of differential geometry (Graduate texts in mathematics 191); Springer Verlag, New York, 1999.

6. Quarteroni A., R. Sacco, and F. Saleri: Numerische Mathematik 1 \& 2; Springer Verlag, Berlin, 2002.

7. Dennis J.E. and R.B. Schnabel: Numerical methods for unconstrained optimization and nonlinear equations; SIAM, 1996.

8. Baker R.R.: The viscous and inertial flow of air through perforated papers; Beitr. Tabakforsch. Int. 14 (1989) 253-260.

9. Keith C.H.: Pressure Drop - Flow Relationships in Cigarette Filter Rods and Tobacco Columns; Beitr. Tabakforsch. Int. 11 (1982) 115-121.

10. Krantz S.G. and H.R. Parks: A primer of real analytic functions; Birkhäuser Verlag, Boston, 2002.

\section{Address for correspondence}

Bernhard Eitzinger

WFT Research

Fabrikstrasse 20

4050 Traun

Austria

E-mail: Bernhard.Eitzinger@traun.tbggroup.com 